\title{
ERITEMA MULTIFORME - UMA APRESENTAÇÃO RARA DE RICKETTSIOSE AGUDA
}

Hugo de Castro Faria', Andreia Mota', Vera Viegas², Alexandra Emilio², Marisa Vicente ${ }^{3}$

'Interno(a) do Internato Complementar de Pediatria/Resident of Pediatrics, Centro Hospitalar de Setúbal

${ }^{2}$ Assistente Hospitalar de Pediatria/Consultant of Pediatrics, Centro Hospitalar de Setúbal

${ }^{3}$ Assistente Hospitalar Graduada de Pediatria/Graduated Consultant of Pediatrics, Centro Hospitalar de Setúbal

Hospital de São Bernardo, Centro Hospitalar de Setúbal, Portugal

RESUMO - O eritema multiforme é uma alteração cutânea de etiologia e fisiopatologia mal conhecidas, mas tem sido descrito em associação a múltiplas patologias infecciosas e inflamatórias. A Ricketsia conori é um agente bem conhecido e descrito na literatura, podendo apresentar um leque variado de manifestações clínicas. A associação entre este agente infeccioso e o eritema multiforme, apesar de referida em algumas revisões na literatura, é extremamente rara e mal conhecida. Neste artigo, descrevemos um caso clínico de infecção a Ricketsia Conori, com confirmação laboratorial numa criança de 9 anos que se apresentou com síndrome febril e eritema multiforme.

PALAVRAS-CHAVE - Eritema multiforme; Infecções por Rickettsia.

\section{ERYTHEMA MULTIFORME - A RARE PRESENTATION OF ACUTE RICKETTIOSIS}

ABSTRACT - Erythema multiforme is a skin disorder of unknown etiology and pathophysiology poorly known, but has been described in association with multiple inflammatory and infectious diseases. Ricketsia conori is a well known and broadly described infectious agent, with a wide range of clinical manifestations. The association between this infectious agent and erythema multiforme, although mentioned in some reviews, is extremely rare and poorly known. In this report we describe a case of Ricketsia conori infection, with laboratorial confirmations, in a 9 year's old child who presented with a febrile syndrome and erythema multiforme.

KEY-WORDS - Erythema multiforme; Rickettsia.

\footnotetext{
Conflitos de interesse: Os autores declaram não possuir conflitos de interesse.

No conflicts of interest.

Suporte financeiro: $O$ presente trabalho não foi suportado por nenhum subsídio ou bolsa.

No sponsorship or scholarship granted.

Direito à privacidade e consentimento escrito / Privacy policy and informed consent: Os autores declaram que pediram consentimento ao doente para usar as imagens no artigo. The authors declare that the patient gave written informed consent for the use of its photos in this article.
}

Recebido/Received - Junho/June 2013; Aceite/Accepted - Julho/July 2013

Por decisão dos autores, este artigo não foi redigido de acordo com os termos do novo Acordo Ortográfico. 


\title{
Caso Clínico
}

\author{
Correspondêncio: \\ Dr. Hugo de Castro Faria \\ Serviço de Pediatria \\ Hospital de S. Bernardo \\ Centro Hospitalar de Setúbal \\ Rua Camilo Castelo Branco \\ 2910-446 Setúbal, Portugal \\ E-mail: hugocfaria@gmail.com
}

\section{INTRODUÇÃO}

O eritema multiforme é uma alteração cutânea aguda, autolimitada e por vezes recorrente. A sua etiologia é mal conhecida mas sabe-se que corresponde a uma reacção de hipersensibilidade tardia desencadeada por estímulos alérgicos ou infecciosos. Este fenómeno tem sido relacionado a múltiplos factores desencadeantes, nomeadamente infecciosos (mais frequentemente Herpes simples 1 e 2 e Mycoplasma pneumoniae), reacções medicamentosas (anti-inflamatórios não esteróides, sulfonamidas, antibióticos, antiepilépticos, entre outros). É caracterizado pelo aparecimento de lesões cutâneas papulares em alvo. Por vezes estas são acompanhadas de bolhas e erosões na mucosa oral, genital ou ocular. A esta associação de afecção cutâneo-mucosa denomina-se eritema multiforme major. Eritema multiforme minor refere-se a doença apenas com envolvimento cutâneo. Tem caracteristicamente uma distribuição acral.

A Ricketsiose é uma infeção multissistémica com múltiplas e variadas manifestações. Em Portugal a mais prevalente é a Rickettsia conori cuja forma de apresentação mais frequente é a febre escaro-nodular. Esta define-se pela tríade de febre, exantema e escara de inoculação. Tipicamente ocorre um início brusco de febre alta, cefaleia intensa e mialgias, três a cinco dias depois surge exantema maculo-papulo-nodular, róseo, purpúrico ou petequial, habitualmente não pruriginoso, que se dissemina em 24 a 36 horas, e persiste 15 a 20 dias. Habitualmente inicia-se nos membros inferiores estendendo-se para o tronco membros superiores, atingindo palmas e plantas. Sem terapêutica adequada o exantema dura oito a onze dias. A escara de inoculação é detectada em até $90 \%$ dos casos, mas pode estar ausente, o que pode traduzir, por exemplo, inoculação através da mucosa ocular.

A associação entre eritema multiforme e rickettsiose é referida em alguns trabalhos de revisão desta afecção cutânea, contudo não encontrámos qualquer descrição de caso com a associação Rickettsia conori e eritema multiforme.

\section{CASO CLÍNICO}

Criança de 9 anos de idade, sexo feminino, previamente saudável, sem antecedentes pessoais ou familiares relevantes, residente em meio rural, contacto habitual e próximo com cães, que desenvolveu quadro inicial caracterizado por odinofagia, otalgia bilateral, mialgias generalizadas, mal-estar geral e febre com temperatura axilar máxima de $38.3^{\circ} \mathrm{C}$. Ao quarto dia de doença ocorreu melhoria do quadro, com alívio das queixas de odinofagia, otalgia e febre, mas mantendo sempre as queixas de mal estar geral, mialgias e astenia. Ao nono dia de doença reiniciou febre alta e difícil de ceder, prostração e exantema exuberante eritematoso

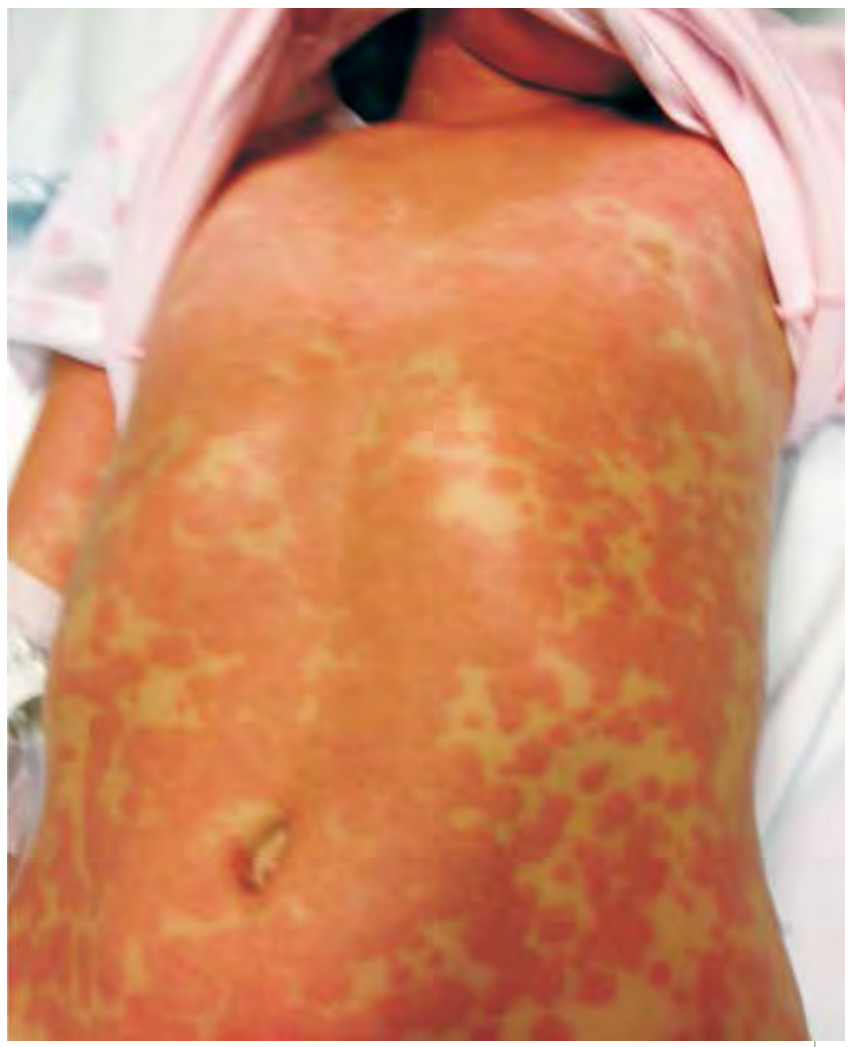

Fig. 1 - Exantema à apresentação. 


\section{Caso Clínico}

disperso, muito pruriginoso. Foi medicada com anti-histamínico pelo médico assistente, sem melhoria. No dia seguinte, por persistência do quadro, recorreu ao Serviço de Urgência Pediátrico do nosso hospital. Do exame objectivo destacava-se prostração, exantema máculo-papular eritematoso exuberante, de bordos elevados, confluente, generalizado, com atingimento de palmas e plantas (Fig. 1), enantema vesicular de predomínio do palato mole, hiperémia conjuntival, restante exame objectivo sem alterações dignas de registo. Analiticamente destacava-se hemoglobina de $11.6 \mathrm{~g} / \mathrm{dL}, 13400$ leucócitos/uL, com predomínio de neutrófilos (91\%), proteína $C$ reactiva de $2.8 \mathrm{mg} / \mathrm{dL}$, análise sumária de urina e radiografia do tórax sem alterações significativas. Decidiu-se internamento para vigilância, medicada com metilprednisolona ev (2 $\mathrm{mg} / \mathrm{kg} / \mathrm{dia})$ e clemastina ev. Ao segundo dia de internamento ocorreu evolução do exantema, que se tornou papular, de bordos elevados, em alvo, muito sugestivo de eritema multiforme (Fig. 2). Para esclarecimento etiológico, foram pedidas serologias para EBV, CMV, HSV, Parvovirus B19, Mycoplasma, que foram negativas, hemocultura (estéril). Foi posteriormente colhida serologia para Rickettsia que revelou

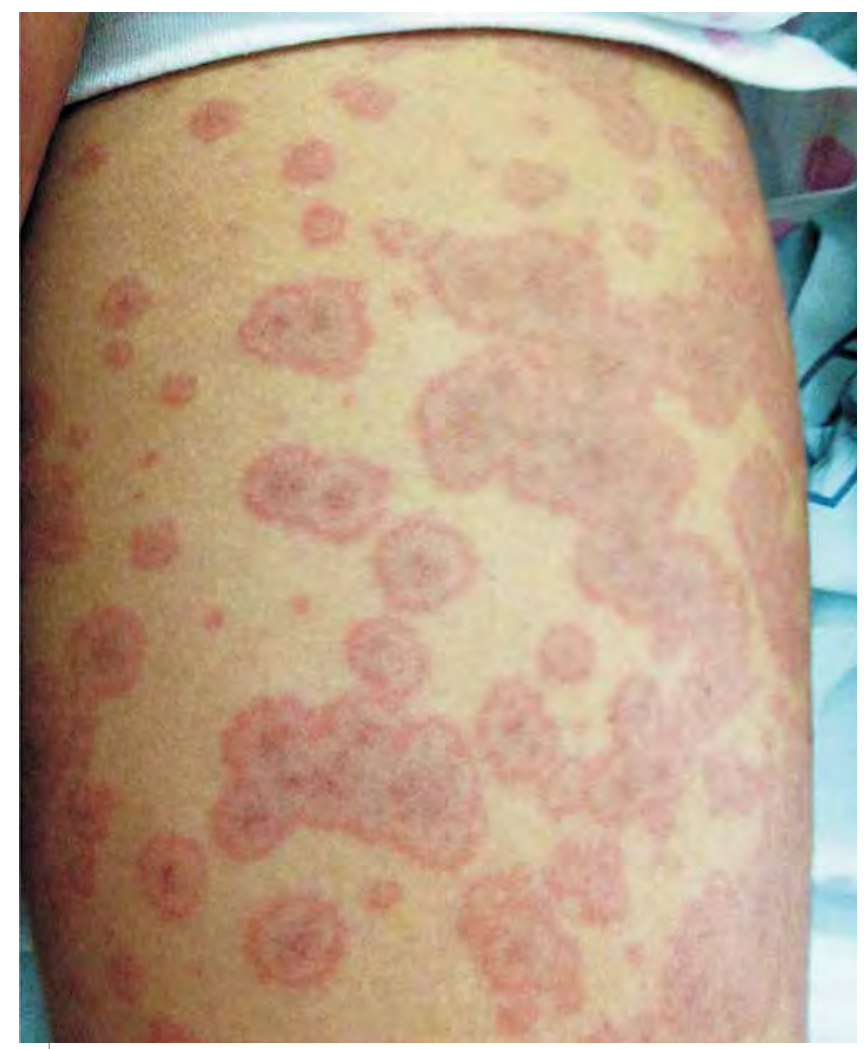

Fig 2 - Eritema multiforme. $\lg M$ e lgG positivas, sugestivas de infecção recente para este agente. A repetição da serologia 3 semanas mais tarde revelou elevação do título superior a quatro vezes o título inicial, reforçando a hipótese de infecção aguda por Rickettsia. A pesquisa por PCR para Ricketsia conori foi positiva.

Ficou apirética após o segundo dia de internamento (décimo segundo dia de doença), mas manteve ainda prostração e mal-estar estar geral importante. Após resultado da serologia para Ricketsia, a criança foi medicada com doxicilina oral durante 5 dias. $O$ eritema multiforme apresentou regressão progressiva, com resolução total ao fim de cerca de 10 dias. A criança encontra-se actualmente assintomática.

\section{DISCUSSÃO}

Trata-se de um caso de eritema multiforme major (uma vez que apresenta atingimento da mucosa oral) causado por infecção por Ricketsia conori.

Esta é uma forma de apresentação rara de rickettsiose. Não foi possível detectar a típica tache-noir, na história não existe referência a picada de carraça, e a evolução da febre foi também atípica (febre recorrente e não persistente e prolongada como habitualmente descrito nestes casos). A associação de infecção a Ricketsia e eritema multiforme está descrita na literatura, mas é extremamente rara. Utilizando a base de dados Pubmed não conseguimos encontrar qualquer descrição de caso clínico com esta associação, existe contudo referência a esta etiologia rara para o eritema multiforme em algumas revisões sobre deste fenómeno dermatológico'.

Neste caso, ocorreu atraso na instituição da terapêutica adequada devido à ausência de história sugestiva de exposição e sinais clínicos típicos. No entanto, pareceu-nos pertinente o estudo etiológico deste agente, uma vez que o exantema neste tipo de infecção pode estar ausente ou ser atípico em cerca de $20 \%$ dos casos.

Numa região endémica para Ricketsia, como é a região do Estuário do Sado, é importante ponderar a sua inclusão no estudo infeccioso de quadros clínicos de provável etiologia infecciosa, ainda que com apresentação atípica.

\section{BIBLIOGRAFIA}

1. Huff JC. Erythema multiforme. Dermatol Clin 1985; 3:141.

2. Huff JC, Weston WL, Tonnesen MG. Erythema 


\section{Caso Clínico}

multiforme: a critical review of characteristics, diagnostic criteria, and causes. J Am Acad Dermatol 1983; 8:763.

3. French LE, Prins C. Erythema multiforme, Stevens- Johnson syndrome, and toxic epidermal necrolysis. In: Dermatology. Bolognia, JL, Jorizzo JL, Rapini RP, editors. Philadelphia: Elsevier Limited; 2008. p.287.

4. Roujeau JC. Erythema multiforme. In: Fitzpatrick's Dermatology in General Medicine, Wolff K,
Goldsmith LA, Katz SI, et al, editors . New York: McGraw-Hill Companies; 2008. p.343.

5. Walker DH. Rickettsiae and rickettsial infections: the current state of knowledge. Clin Infect Dis. 2007; 45 (Suppl 1):S39-44.

6. Center of Disease Control and Prevention (CDC). Rickettsial Diseases. Infectious Disease Information. [consultado em Jan 2013]. Disponível: http://www. cdc.gov/ncidod/dvrd/branch/vrzb.htm. 